\title{
Dynamic stress analysis of anisotropic gun barrel under coupled thermo-mechanical loads via finite element method
}

\author{
Yuzhao Yang ${ }^{\mathrm{a}}$ (D) Xiaoyun Zhang ${ }^{\mathrm{a}}$ (D), Cheng $\mathrm{Xu}^{\mathrm{a}}$ (D), Lixia Fan ${ }^{\mathrm{a}^{*}}$ (iD) \\ a School of Mechanical Engineering, Nanjing University of Science and Technology, Nanjing 210094, P.R. China. \\ E-mail: yangyuzhao@njust.edu.cn, xyzhang531@163.com, xucheng62@mail.njust.edu.cn, fanlixia151@njust.edu.cn \\ ${ }^{*}$ Corresponding author
}

http://dx.doi.org/10.1590/1679-78255800

\begin{abstract}
This work focused on the stress response of anisotropic 30SiMn2MoVA steel gun barrel under coupled thermo-mechanical loads, namely, the contact pressure and friction of projectile, thermal load and pressure of propellant gas. The effect of temperature on the mechanical properties of gun barrel was considered. Two thermal-displacement coupled finite element models (FEM) were built by ABAQUS software. The first was the interaction model of projectile and barrel which was to calculate the stress of barrel engraved by copper jacket and steel jacket projectile. The results of barrel in the interaction model, as an initial condition, were imported to the second FEM which was applied with thermal load and pressure of propellant gas. The results show that the rifling at chamber throat has the largest stress and circumferential stress under coupled loads. It gives a request that the gun barrel should have the better circumferential mechanical properties. The plastic deformation of the rifling at the chamber throat is observed which indicates that 30SiMn2MoVA gun barrel has a low service life due to the poor mechanical properties.
\end{abstract}

\section{Keywords}

30SiMn2MoVA steel; anisotropic gun barrel; stress response; coupled thermo-mechanical loads; copper jacket and steel jacket projectile; thermal load and pressure of propellant gas

\section{Graphical Abstract}

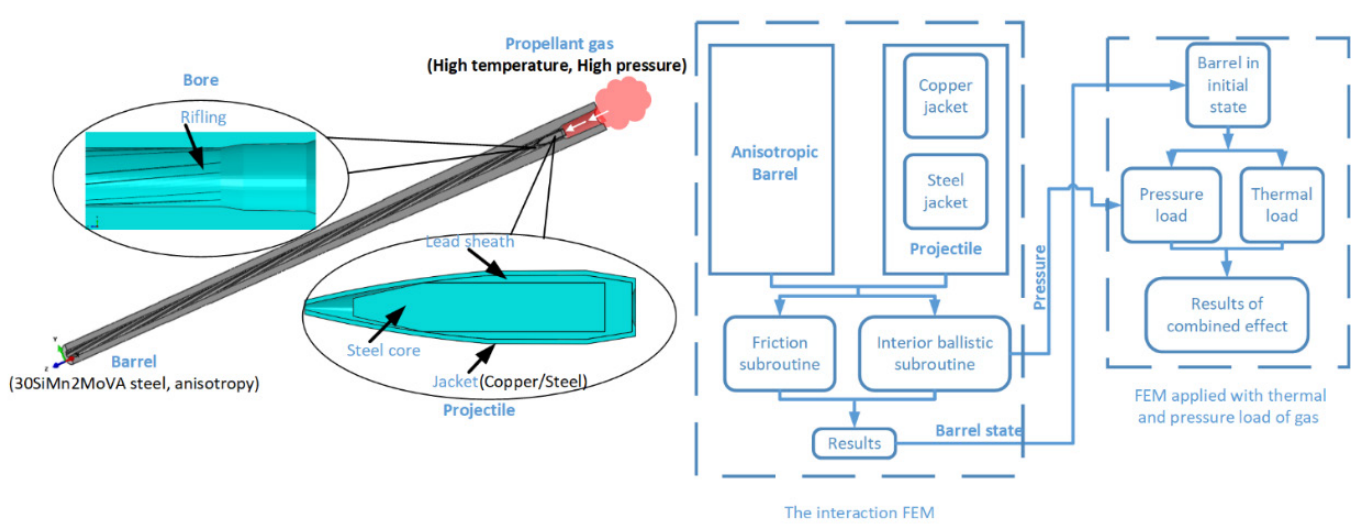




\section{INTRODUCTION}

30SiMn2MoVA steel has been used for the gun barrel for many years in China. However, the barrel made from this material has a lower service life than expected. Most researchers had confirmed that 30SiMn2MoVA steel barrel processed by cold radial forging was obviously anisotropy that the circumferential mechanical properties were inferior to the axial (Liu et al., 2012). Xu et al. (2016) reported the main reason of anisotropy was preferred orientation of crystals (texture) during the cold radial forging processing. As an efficient process, most of barrels are produced by cold radial forging. Hence, the anisotropy should be considered in the stress analysis and design of 30SiMn2MoVA steel gun barrel.

Generally, when the engineers check the strength of barrel, the gun barrel is assumed to a thick-walled cylinder without rifling. Different classical strength theories were selected to calculate the stress state of barrel under the maximum internal pressure (Zhao et al., 1997). The relevant calculation was simple and easy to be solved under that assumption. Nonetheless, when firing, there was not only gas pressure but also thermal load, contact pressure and friction of projectile. With the development of finite element analysis, the stress analysis of barrel, mainly embodied in the application of loads, is close to reality gradually. Some researchers calculated the stress states of the whole barrel according the gas pressure distribution in bore (Zhang et al.,2015, Degirmenci, 2015, Güngor et al.,2018). Yu et al. (2018) considered the contact pressure of projectile and gas pressure distribution. In their work, a user-defined load subroutine was developed in the ABAQUS to simulate the moving and changing of gas pressure load. Meanwhile, some researchers focused on the thermal load of propellant gas. Degirmenci et al. (2012) provided an approach to determine the heat transfer coefficients in a gun barrel. Noh et al. (2018) reported an inverse heat conduction model to calculate the temperature field of barrel. Most of investigations were carried to calculate the stress state considering the coupled thermal load and pressure of gas. Fan et al. (2006) investigated the temperature field and thermo-pressure stress and deformation of water-cooled gun barrel. Other similar researches showed the thermo-pressure stress of barrel with different caliber or different propellant powder (Qu et al., 2014, Degirmenci et al., 2016, Evci et al.,2018). In terms of the effect of projectile on barrel, the interaction of barrel and projectile has been investigated based on FEA for a long time. Most studies mainly focused on the deformation and movement of projectile (Jiang et al., 2008, Wu et al.,2014, KEINANEN et al.,2012, Li et al.,2016, Yang et al., 2018). Using the similar research method, some researchers analyzed the state of barrel. Liu et al. (2015) built a damage mechanics finite element method based on microscopic damage model to investigate the damage, crack initialization and growth in bore. Ding et al. (2016) designed a piecewise-connection algorithm to generate parametric 3D solid model of bore to analyze the worn gun barrel based on projectile-barrel interaction model. Li et al. (2019) investigated the wear of the inner wall of the gun barrel and simulated the interaction of projectile and barrel under different wear conditions.

Based on the above analysis, a large number of studies had been carried out on the topic of the effect on the barrel of propellant gas or projectile, but the study considering the combined effect of propellant gas and projectile is rare. This work provided a method to calculate the joint influence. The process was divided into two thermal-displacement coupled FEMs. The first was the interaction model of projectile and barrel which was applied to obtain the results of barrel engraved by projectile. After that, the results of the interaction model were imported to the second FEM applied with thermal load and pressure of propellant gas. As an innovation, the material of barrel in the FEM was 30SiMn2MoVA steel barrel which was plasticity anisotropy. The effect of temperature on the mechanical properties of barrel was also considered.

\section{ESTABLISHMENT OF THE FINITE ELEMENT MODEL}

The scheme of establishing the finite element model is shown in Figure 1. The propellant gas is enclosed at the bottom of the projectile. With the moving forward of projectile, propellant gas gradually contacts the surface in bore. In other words, the bore interacts with the projectile firstly and then bears the propellant gas. There are two models. The first is the interaction FEM of barrel and projectile. There is only one part in the second FEM, namely, gun barrel. The initial state of the barrel in the second FEM is obtained from the result of the first FEM. Then the barrel is applied with thermal load and pressure from propellant gas to calculate the combined effect of projectile and propellant gas. 


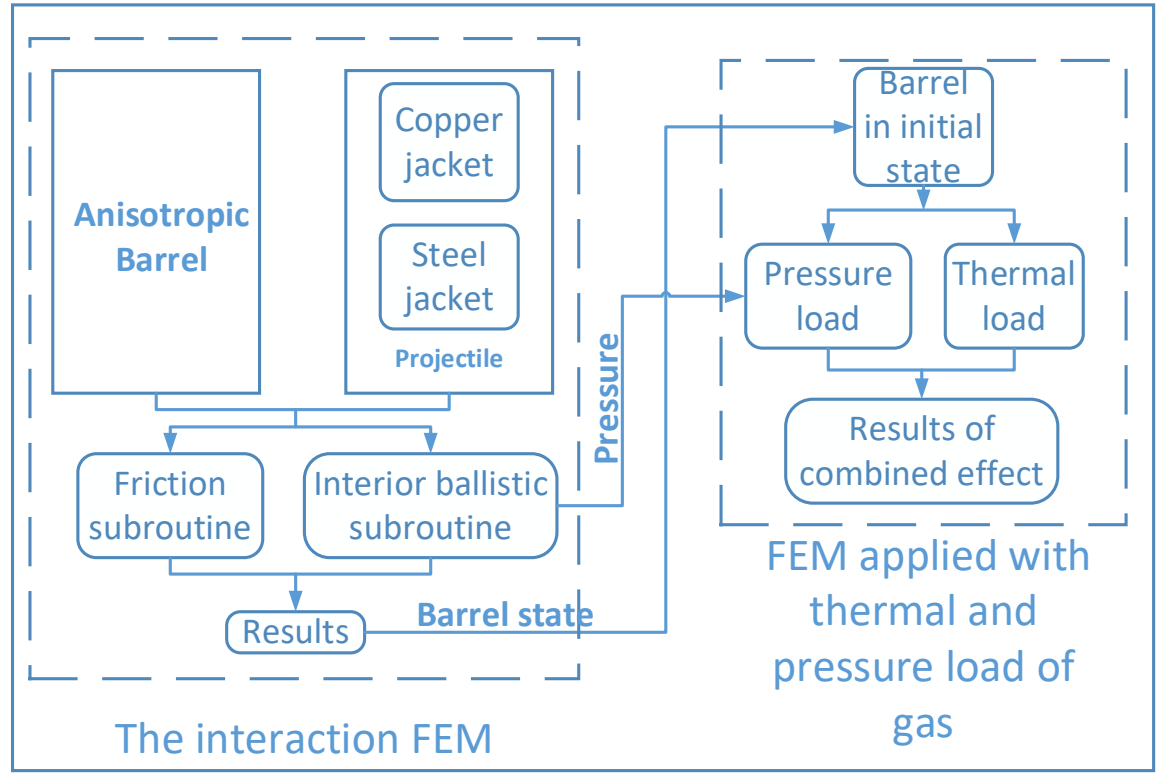

Figure 1. The scheme of establishing the finite element model.

According to the structural parameters of the projectile and barrel of a 5.8mm caliber automatic rifle, a three-dimensional model was established and meshed. The element type is 8-node thermally coupled brick, trilinear displacement temperature, reduced integration, hourglass control (C3D8RT) element. The whole model contains 281182 elements. The assembly is shown in Figure 2. The chromium layer in the bore was ignored.

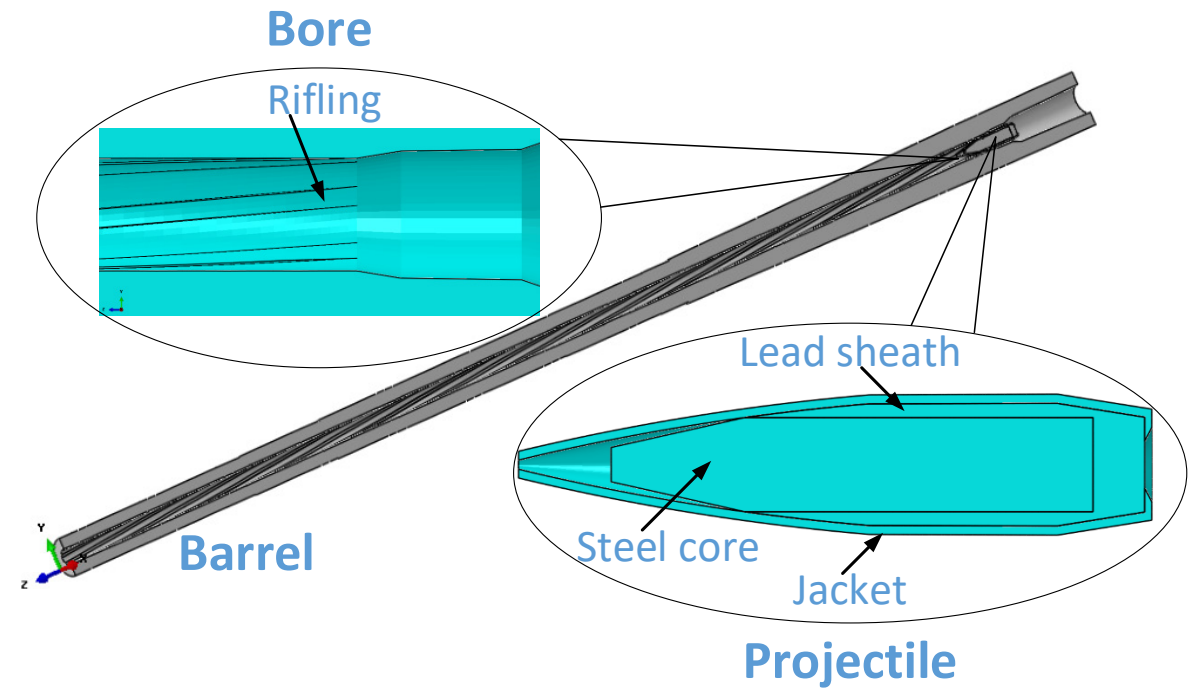

Figure 2. The assembly of projectile and barrel.

\subsection{Material properties}

\subsubsection{Barrel Material}

Gun barrel was made from 30SiMn2MoVA steel by cold radial forging. The barrel was obviously anisotropy. The axial yield strength was higher than the circumferential. There are many yield criterions to describe the plasticity anisotropy for different materials and stress states. As the first orthotropic yield function, Hill 1948 yield criterion (Hill, 1950) was widely used because of its simplicity. In this work, the Hill 1948 yield criterion was used in barrel material. It is written in the following form in the cylindrical coordinate.

$F\left(\sigma_{r}-\sigma_{z}\right)^{2}+G\left(\sigma_{z}-\sigma_{\theta}\right)^{2}+H\left(\sigma_{\theta}-\sigma_{r}\right)^{2}+2 L \tau_{r z}^{2}+2 M \tau_{\theta z}^{2}+2 N \tau_{r \theta}^{2}=2 \sigma_{e}^{2}$ 
where $\sigma_{e}$ is the equivalent stress, $\sigma_{r}, \sigma_{z}$ and $\sigma_{\vartheta}$ are the radial, axial and transverse stress, $F, G, H, L, M$ and $N$ are material parameters. The barrel is thick-walled cylinder and is assumed under plane strain condition $\left(\tau_{r z}=\tau_{\theta z}=\tau_{r \theta}=0\right.$ ). Under this condition, Saux et al. (2008) suggested that shear components could be assumed to be equal to the isotropic ones, i.e. $L=M=N=1.5$. Three independent anisotropic parameters must be identified $(F, G$ and $H)$ which can be calculated in the formula (2). The $X, Y$ and $Z$ are uniaxial tensile yield stress in the main direction of anisotropy.

$$
\left\{\begin{array}{l}
\frac{1}{X^{2}}=G+H \\
\frac{1}{Y^{2}}=F+H ｝ \\
{\frac{1}{Z^{2}}=F+G}
\end{array},
\end{array}\right.
$$

According to the test methods proposed by Liu et al. (2012), the material properties of 30SiMn2MoVA steel barrel at room temperature could be obtained by experiment and were shown in Table 1 . The radial properties were assumed to be the same as the circumferential.

Table 1 The axial and transverse mechanical properties

\begin{tabular}{|c|c|c|c|c|}
\hline & Young's modulus/GPa & Yield strength/MPa & Tensile strength/MPa & Elongation/\% \\
\hline Axial & 215 & 997 & 1101 & 17.80 \\
\hline Circumferential & 213 & 900 & 1117 & 15.52 \\
\hline
\end{tabular}

The effect of temperature on the mechanical properties is obvious. The strength of barrel sharply decreased under the high temperature. Cao et al. (2017) proposed the empirical formulas to calculate the yield strength and modulus of elasticity of $30 \mathrm{Simn} 2 \mathrm{MoVA}$ steel barrel under $600^{\circ} \mathrm{C}$ according to the results of high-temperature tensile test. The empirical formula for yield strength is:

$$
\frac{R_{p 0.2}(T)}{R_{p 0.2}}=-0.047 \times\left(\frac{T}{293 K}\right)^{4}+0.201 \times\left(\frac{T}{293 K}\right)^{3}-0.15 \times\left(\frac{T}{293 K}\right)^{2}-0.376 \times\left(\frac{T}{293 K}\right)+1.375
$$

where $R_{p 0.2}$ is the yield strength at the room temperature. The empirical formula for Young's modulus is:

$$
\frac{E(T)}{E}=-0.025 \times\left(\frac{T}{293 K}\right)^{2}+0.04 \times\left(\frac{T}{293 K}\right)+0.985
$$

When the temperature exceeds $600^{\circ} \mathrm{C}$, the above formulas are no longer applicable. 30SiMn2MoVA steel is high strength steel. Chen et al. (2006) investigated the mechanical properties of several high strength steels under $1000^{\circ} \mathrm{C}$ and proposed the ratios of mechanical properties at high temperature to that at room temperature. Hence, the relevant mechanical properties of 30SiMn2MoVA steel beyond $600^{\circ} \mathrm{C}$ could be calculated referring to the Chen's work.

The other thermophysical parameters of 30SiMn2MoVA steel barrel needed in the FEM can be obtained from the relevant references and are listed in Table 2.

Table 2 Thermophysical parameters of 30SiMn2MoVA steel barrel (Gu et al.,2018)

\begin{tabular}{ccccc}
\hline$T / K$ & $\begin{array}{c}\text { Thermal } \\
\text { conductivity } \\
/ \mathbf{W} \cdot \mathbf{m}^{-1} \cdot \mathbf{K}^{-1}\end{array}$ & $\begin{array}{c}\text { Specific heat } \\
/ \mathbf{J} \cdot \mathbf{k g}^{-1} \cdot \mathbf{K}^{-1}\end{array}$ & Poisson ratio & Expansion coeff $/ \mathrm{K}^{-1}$ \\
\hline 293 & 33.8 & 480.3 & 0.29 & $1.25 e-5$ \\
573 & 32.0 & 538.2 & 0.295 & - \\
873 & 31.0 & 595.1 & 0.3 & - \\
1173 & 30.5 & 634.2 & 0.316 & - \\
\hline
\end{tabular}




\subsubsection{Jacket Material}

The jacket of projectile contacts the barrel directly. Under the extrusion of rifling, the surface material of jacket undergoes plastic deformation and forms notches. Different jackets make different effects on barrels. Copper jacket projectile and steel jacket projectile are commonly used for this type of gun barrel.

\section{1). Copper jacket}

Many firing tests confirmed that the copper material would be come off the surface of copper jacket. In order to describe this behavior accurately, the Johnson-Cook constitutive model (Johnson et al.,1985) was applied to copper jacket which was

$$
\sigma=\left[A+B(\varepsilon)^{n}\right]\left[1+C \ln \left(\frac{\dot{\varepsilon}}{\dot{\varepsilon}_{0}}\right)\right]\left[1-\left(\frac{T-T_{r}}{T_{m}-T_{r}}\right)^{m}\right]
$$

where $\sigma, \varepsilon, \dot{\varepsilon}$ and $\dot{\varepsilon}_{0}$ are the equivalent stress, plastic strain, plastic strain rate and reference strain rate, $A, B, C, n$ and $m$ are material constants, $T, T_{r}$ and $T_{m}$ are real-time temperature, reference temperature (room temperature) and melting point of copper materials. Johnson-Cook damage criterion was applied to judge whether the material was invalid or not. Its form is

$\varepsilon_{d}=\left(d_{1}+d_{2} e^{-d_{3} \eta}\right)\left[1+d_{4} \ln \left(\frac{\dot{\varepsilon}}{\dot{\varepsilon}_{0}}\right)\right]\left[1+d_{5}\left(\frac{T-T_{r}}{T_{m}-T_{r}}\right)\right]$

where $d_{1} \sim d_{5}$ are material constants. When the damage value of the element reaches 1 , the element fails and is deleted. $D$ is the disruption displacement of damage evolution. The copper material constants were shown in the Table 3. Additionally, the thermophysical parameters of copper jacket were shown in the Table 4.

Table 3 Material parameters of copper jacket (Ding et al., 2015)

\begin{tabular}{|c|c|c|c|c|c|c|}
\hline$A / \mathrm{MPa}$ & $B / \mathrm{MPa}$ & C & $n$ & $m$ & $\mathrm{~T}_{\mathrm{m}} / \mathrm{K}$ & $\mathrm{T}_{\mathrm{r}} / \mathrm{K}$ \\
\hline 90 & 292 & 0.025 & 0.31 & 1.09 & 1331 & 298 \\
\hline $\mathrm{d}_{1}$ & $\mathrm{~d}_{2}$ & $d_{3}$ & $d_{4}$ & $d_{5}$ & $\dot{\varepsilon}_{0} / \mathrm{s}^{-1}$ & $D / \mathrm{mm}$ \\
\hline 0.54 & 4.89 & 3.03 & 0.014 & 1.12 & 1 & 0.1 \\
\hline
\end{tabular}

Table 4 Thermophysical parameters of copper jacket (Ding et al., 2015)

\begin{tabular}{|c|c|c|c|c|c|}
\hline$T / K$ & $\begin{array}{c}\text { Young's modulus } \\
\text { /GPa }\end{array}$ & $\begin{array}{l}\text { Specific heat } \\
/ \mathrm{J} \cdot \mathrm{Kg}^{-1} \cdot \mathrm{K}^{-1}\end{array}$ & $\begin{array}{l}\text { Thermal } \\
\text { conductivity } \\
\text { /W. } \mathbf{m}^{-1} \cdot \mathrm{K}^{-1}\end{array}$ & Expansion coeff/ $\mathrm{K}^{-1}$ & Density $/ \mathrm{Kg} \cdot \mathrm{m}^{-3}$ \\
\hline 298 & 123 & 383 & 386 & $1.78 \mathrm{e}-5$ & 8960 \\
\hline 403 & 117 & 400 & 382 & $1.78 \mathrm{e}-5$ & - \\
\hline 603 & 102 & 420 & 352 & $1.88 e-5$ & - \\
\hline 903 & 90 & 450 & 338 & $2.09 e-5$ & - \\
\hline
\end{tabular}

\section{2). Steel jacket}

The material of steel jacket is F18 copper clad steel. In the process of engraving with the bore, the material of steel jacket rarely falls off. Elastoplastic constitutive model was employed to describe the deformation behavior. The engineering stress-strain curve was shown in Figure 3. the relevant material parameters of steel jacket in the FEM was shown in Table 5. 


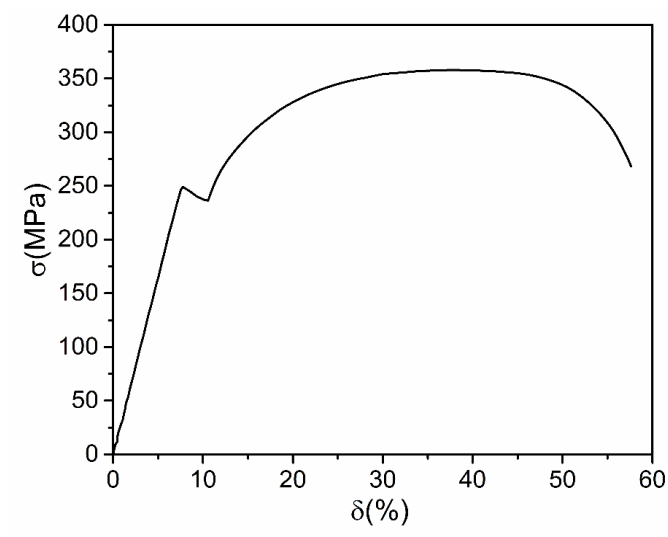

Figure 3. The stress strain curve of F18 copper clad steel (Yuan et al., 2012)

Table 5 Material parameters of steel jacket (Yuan et al., 2012)

\begin{tabular}{|c|c|c|c|c|c|}
\hline Poisson ratio & $\begin{array}{l}\text { Young's modulus } \\
\text { /GPa }\end{array}$ & $\begin{array}{l}\text { Specific heat } \\
/ \mathrm{J} \cdot \mathrm{Kg}^{-1} \cdot \mathrm{K}^{-1}\end{array}$ & $\begin{array}{l}\text { Thermal } \\
\text { conductivity } \\
\mathrm{IW} \cdot \mathrm{m}^{-1} \cdot \mathrm{K}^{-1}\end{array}$ & Expansion coeff / $\mathrm{K}^{-1}$ & $\begin{array}{l}\text { Density } \\
/ \mathrm{Kg} \cdot \mathrm{m}^{-3}\end{array}$ \\
\hline 0.3 & 210 & 480 & 40 & $1.25 e-5$ & 7850 \\
\hline
\end{tabular}

\subsubsection{The material properties of the rest parts}

The material of lead sheath was described by elastoplastic constitutive model, steel core for elastic model. Some of their material parameters were shown in Table 6.

Table 6 Material parameters of the rest parts (Yang et al., 2018)

\begin{tabular}{|c|c|c|c|c|c|}
\hline Part & $\begin{array}{l}\text { Young's modulus } \\
\text { /GPa }\end{array}$ & Poisson ratio & Density $/ \mathrm{Kg} \cdot \mathrm{m}^{-3}$ & $\begin{array}{c}\text { Specific heat } \\
/ \mathrm{J} \cdot \mathrm{Kg}^{-1} \cdot \mathrm{K}^{-1}\end{array}$ & $\begin{array}{c}\text { Thermal } \\
\text { conductivity } \\
/ \mathbf{W} \cdot \mathbf{m}^{-1} \cdot \mathbf{K}^{-1}\end{array}$ \\
\hline Steel core & 190 & 0.3 & 8580 & 460 & 40 \\
\hline Lead sheath & 17 & 0.42 & 11340 & 130 & 35 \\
\hline
\end{tabular}

\subsection{Contact}

The steel core, lead sheath and jacket were tied each other in ABAQUS. There was no sliding between them. In this section, the contact between jacket and barrel was studied, specifically, the friction and heat transfer between jacket and barrel.

\subsubsection{Friction coefficient}

When firing the copper jacket projectile, the copper material would come off the surface of the jacket. For friction, most of studies suggested that the classical coulomb friction model was not applicative in that situation but shear-slip model was appropriate, namely, modified coulomb friction model. The relationship between ultimate shear stress and frictional shear stress is considered in shear-slip model. And the frictional shear stress $\tau_{f}$ is expressed by

$\tau_{f}=\min \left(\mu \sigma_{n}, \tau_{s}\right)$

where $\mu$ is the friction coefficient, $\sigma_{n}$ is the positive pressure of the contact surface and $\tau_{s}$ is the allowable shear stress of the material. For copper material, Li et al., (2016) proposed a formula to calculate the $\tau_{s}$ considering the temperature of the contact area, which is

$\tau_{s}=\frac{1}{\sqrt{3}} \sigma_{s}\left[1-\left(\frac{T-T_{r}}{T_{m}-T_{r}}\right)^{m}\right]$ 
where the temperature term is the same as formula (5). Ding et al. (2015) investigated the experimental data of friction between copper and steel under high speed and heavy load conditions and proposed a fitting empirical formula about the friction coefficient which is

$\mu=(2 e-11) T^{4}-(2.963 e-8) T^{3}+(1.323 e-5) T^{2}-0.002 T+0.384$

where $T$ is the temperature of contact area. The above shear-slip model could be performed by friction subroutine (VFRICTION) in ABAQUS (Dassault Systemes, 2014).

When firing the steel jacket, plastic deformation was the main behavior for the surface material of jacket. The steel material was hardly damaged and come off. The classical coulomb friction model still worked. Yang et al. (2018) provided an optional friction coefficient which was 0.1 .

\subsubsection{Heat transfer}

The heat of propellant gas would be introduced in the section 2.4. In this part, the heat between jacket and barrel was discussed. The initial temperature of barrel and projectile were set to room temperature, namely, $25^{\circ} \mathrm{C}$. There were two heat source, plastic deformation heat and frictional heat. For plastic deformation heat, the plastic thermal conversion coefficient 6 must be identified. For most metal materials, $90 \%$ of plastic deformation work is converted to heat. Therefore, the $B$ in this FEM was 0.9. In terms of frictional heat, how it was distributed to contact parts needed to be determined. $q_{1}, q_{2}$ are the friction heat flux of barrel bore and jacket surface, respectively. The ratio of that is the distribution coefficient of friction heat. That is

$$
\frac{q_{1}}{q_{2}}=\sqrt{\frac{k_{1} \rho_{2} c_{2}}{k_{2} \rho_{1} c_{1}}}
$$

where $k, \rho$ and $c$ are the thermal conductivity, density and specific heat with corner marker 1 for barrel and marker 2 for jacket.

Additionally, heat transfer between contact surfaces was determined by heat conductivity. A lot of experiments about the heat transfer between metal materials under high speed and pressure conditions had been done by Zhu et al. (2008). The heat conductivity of copper-steel contact and steel-steel contact were chosen from their work.

\subsection{Pressure load of propellant gas}

For the first FEM, the interaction FEM of barrel and projectile, the pressure of propellant gas was only applied to the bottom of the projectile. The amplitude of pressure can be calculated by interior ballistic equation (Ding et al., 2015) which is

$$
\left\{\begin{array}{l}
P=\frac{f \omega(\psi-\eta)-\varphi \theta \frac{m v^{2}}{2}}{S\left(L_{\psi}+L\right)} \\
\psi=\left\{\begin{array}{l}
\chi Z\left(1+\lambda Z+\mu Z^{2}\right), \quad 0<Z<1 \\
\chi Z(1+\lambda Z), \quad Z \geq 1
\end{array}\right. \\
\frac{d Z}{d t}=\frac{\mu_{1}}{e_{1}} P^{n}
\end{array}\right.
$$

where $P$ is average pressure, $f$ is the propellant impetus, $\eta$ is flow coefficient of air guide hole, $\omega$ is the propellant mass, $\psi$ is the relative burned volume, $m$ is the mass of the projectile, $\vartheta$ is thermal index, $S$ is the cross-sectional area of the bore, $L$ and $v$ are the displacement and velocity of the projectile, respectively, $\varphi$ is the secondary energy losses coefficient, $L_{\psi}$ is the ratio of the initial volume to the bore area, $\chi, \lambda$, and $\mu$ are constants for the propellant, $Z$ is the relative burned thickness, $e_{1}$ is the half thickness of the propellant, $n$ is the pressure index of the burning rate, and $\mu_{1}$ is the burning rate. 
The classical interior ballistic equation, implemented using the VUAMP subroutine in ABAQUS (Dassault Systemes, 2014), was coupled in the interaction FEM. The calculation process was shown in Figure 4 . The initial burning quantity of propellant $Z_{0}$ is set in the subroutine. The corresponding bore average pressure $P$ are calculated and loaded on the bottom of the projectile. The corresponding data of projectile velocity $v$, angular velocity $w$, and displacement $u$ are obtained in the ABAQUS solver. Then the displacement value, velocity value and angular velocity value are transmitted back to VUAMP subroutine. It solves the new secondary work coefficient $\varphi$, propellant burning quantity $Z$, chamber pressure $P$ and so on. Then returns to the solver. The displacement and velocity equivalents are solved again. The above steps are repeated until the projectile flies away from the barrel.

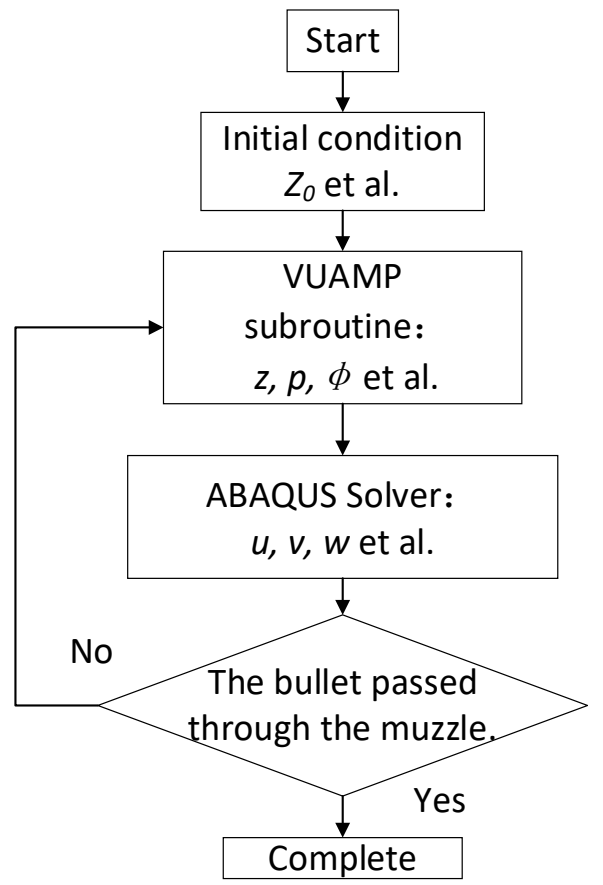

Figure 4. The calculation flow chart

For the second FEM, the pressure of propellant gas was applied to the inner surface of barrel. The pressure varies with time and the movement of projectile. The relationship between pressure and displacement was obtained from the result of the interaction FEM. Then using "Analytical Filed" function in ABAQUS, the non-uniform distribution of pressure along the axial direction in the inner surface of barrel can be solved.

\subsection{Thermal load of propellant gas}

In ABAQUS, the thermal load only can be heat flux. According to the Wu et al. (2005), the heat flux $q_{\text {in }}$ when barrel fires one projectile can be calculated by

$q_{\text {in }}=\frac{H_{s}}{t_{0}} \exp \left(-t / t_{0}\right)$

where $H_{s}$ is a total heat transfer per unit area per round and $t_{0}$ is the time constant. Lawton (2001) proposed the relation between the maximum bore temperature and the heat transfer per round which is 


$$
\left\{\begin{array}{l}
T_{\max }-T_{i}=1.082 \frac{H_{s}}{k} \sqrt{\frac{a}{\pi t_{0}}} \\
t_{0}=\frac{0.8 m v_{m}}{P_{\max } d^{2}} \\
a=\frac{k}{c \rho}
\end{array}\right.
$$

where $T_{\max }$ is the maximum bore temperature, $T_{i}$ is the initial temperature of the barrel, $k$ is the thermal conductivity of gun steel, $a$ is the thermal diffusivity of gun steel, $\rho$ is the density of barrel steel, $c$ is the specific heat of barrel, $m$ is the mass of the projectile, $P_{\max }$ is the maximum pressure, $d$ is the barrel caliber, and $v_{m}$ is the muzzle velocity. According to $\mathrm{Gu}$ et al. (2018), the maximum bore temperature was $460^{\circ} \mathrm{C}$ when fire one projectile. The maximum pressure and velocity can be obtained from the interaction model of barrel and projectile. Then the heat flux can be obtained from the Equ. (12) and (13).

The main heat transfer between the propellant gas and barrel was the forced convective heat transfer. Assuming that radiative heat exchange was $15-20 \%$ of convective heat exchange. The modified forced convection coefficient $\alpha$ was calculated by

$$
\left\{\begin{array}{l}
\alpha=\frac{(1.15 \sim 1.2) \times 0.023 K(t) \operatorname{Re}^{0.8} \operatorname{Pr}^{0.4}}{d} \\
\operatorname{Re}=\frac{\rho(t) v(t) d}{\mu(t)} \\
\operatorname{Pr}=\frac{\mu(t) c(t)}{K(t)}
\end{array}\right.
$$

where Re is Reynolds number, Pr is Plante number, $d$ is barrel caliber, $\rho(t) v(t) \mu(t) c(t)$ and $K(t)$ are the density, velocity, dynamic viscosity, specific heat and capacity thermal conductivity of propellant gas, respectively. The forced convection coefficient $\alpha$ was shown in the Figure 5 (Lan et al.,2017).

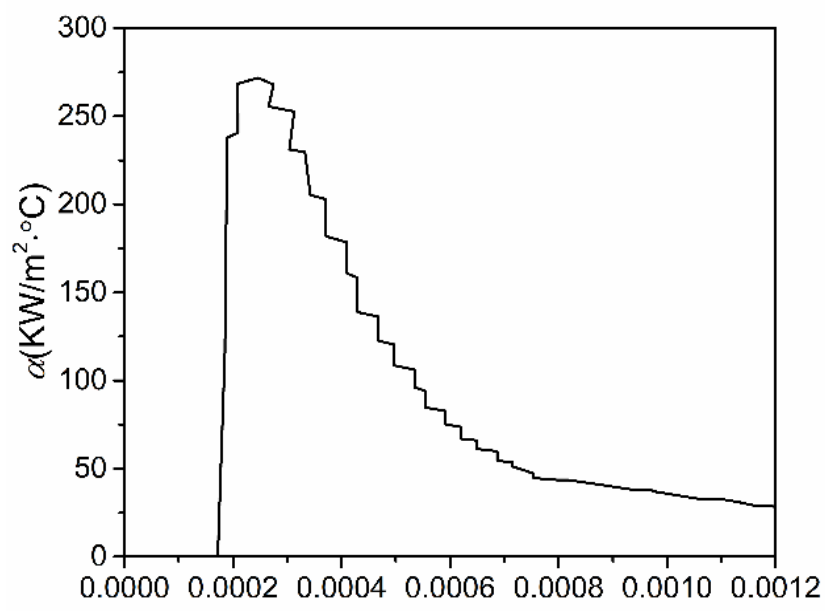

$\mathrm{t}(\mathrm{s})$

Figure 5. The forced convection coefficient $\alpha$ in the interior ballistic period

Additionally, the heat transfer between the barrel and air was considered in the FEM. The atmospheric convection coefficient was set to $26.57 \mathrm{~W} / \mathrm{m}^{2} \mathrm{~K}$. 


\section{MESH DENSITY SENSITIVITY AND FEM VERIFICATION}

The effect of mesh density sensitivity on analysis results was considered. There were three mesh density types of barrel as shown in Figure 6. The number of layers of radial mesh was 8, 6 and 4, respectively. The element size was $0.5 \mathrm{~mm}, 1.0 \mathrm{~mm}$ and $1.5 \mathrm{~mm}$. Considering that the interior ballistic process was sealed off and its time was very short, it was hardly observed and measured by experiment. Most of the relevant researches recommended to verify the FEM by comparing velocity of projectile and the pressure of simulation with the experiments. Therefore, the effect of mesh density was evaluated by comparing the maximum speed and bore pressure of the interaction FEM using copper jacket projectile with the experiment.

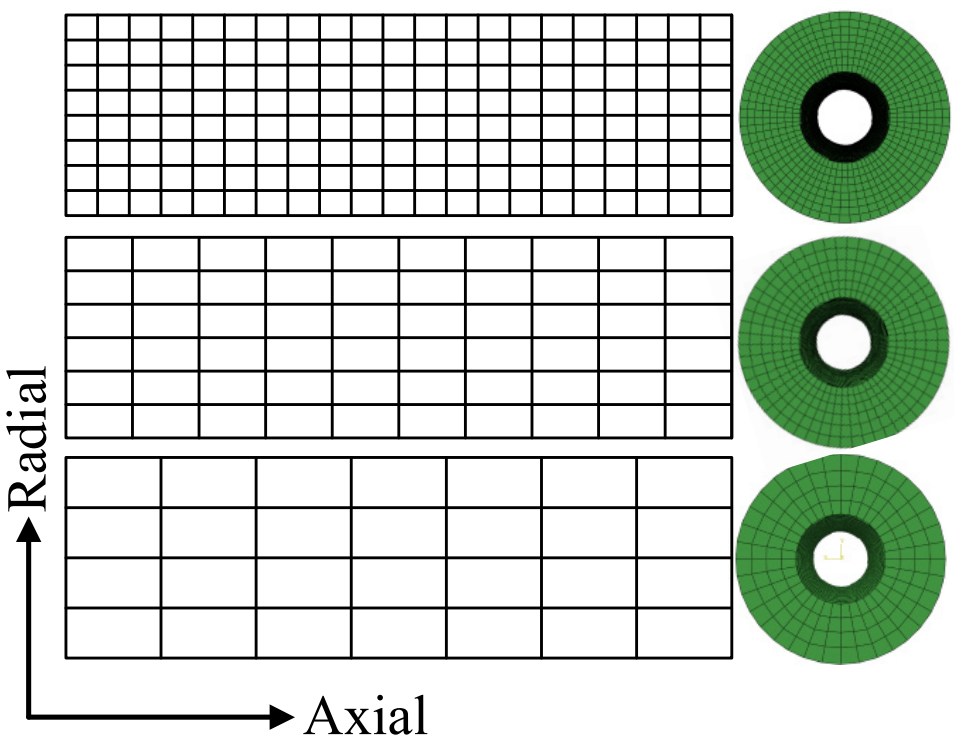

Type 1

Radial: 8 layers

Axial and Circumferential element size: $0.5 \mathrm{~mm}$

Type 2

Radial: 6 layers

Axial and Circumferential element size: $1.0 \mathrm{~mm}$

Type 3

Radial: 4 layers

Axial and Circumferential element size: $1.5 \mathrm{~mm}$

Figure 6. The mesh density of barrel

When firing copper jacket projectile, the measured maximum speed of projectile and bore pressure were $920 \mathrm{~m} / \mathrm{s}$ and $287.9 \mathrm{MPa}$. The results of the interaction FEM under different mesh density were shown in Table 7. While the simulation results showed that the chamber pressure was higher than experiment. The reason was that the internal ballistic subroutine only took into account the kinetic energy and rotational work of projectile, friction work and the motion work of propellant gas to calculate the secondary work coefficient. The secondary work coefficient was smaller than the reality.

The mesh density made obvious effect on the simulation results. With the increasing of mesh density, the simulation results were gradually close to the test results. For the mesh density type 1 , the maximum speed of projectile was only $3.1 \%$ higher than the experiment and the bore pressure was 3.75\% higher than the test. However, it took too much time, 117 hours. The mesh density type 3 had the shortest calculation time, but the calculation accuracy was poor. The type 2 had the better comprehensive advantages from the Table 7 and it was chosen to complete the rest of the simulation.

Table 7 The results of the interaction FEM using copper jacket projectile under different mesh density

\begin{tabular}{ccccccc}
\hline Mesh density & $\begin{array}{c}\text { Number of barrel } \\
\text { elements }\end{array}$ & $\begin{array}{c}\text { Actual calculation } \\
\text { time } \\
\text { (h) }\end{array}$ & $\begin{array}{c}\text { Maximum } \\
\text { velocity of } \\
\text { projectile } \\
\text { (m/s) }\end{array}$ & $\begin{array}{c}\text { Error } \\
\text { compared with } \\
\text { experimental } \\
\text { value (\%) }\end{array}$ & $\begin{array}{c}\text { Maximum } \\
\text { bore pressure } \\
\text { (MPa) }\end{array}$ & $\begin{array}{c}\text { Error } \\
\text { compared with } \\
\text { experimental } \\
\text { value (\%) }\end{array}$ \\
\hline Type 1 & 445784 & 117 & 948.57 & $3.1 \%$ & 298.71 & $3.75 \%$ \\
Type 2 & 177102 & 47 & 960.29 & $4.34 \%$ & 301.60 & $4.75 \%$ \\
Type 3 & 68036 & 18 & 993.94 & $8.04 \%$ & 311.02 & $8.03 \%$ \\
\hline
\end{tabular}

Based on the mesh density type 2, the results of the interaction FEM using steel jacket projectile was shown in Table 8 . The measured maximum velocity was $897 \mathrm{~m} / \mathrm{s}$ which was $3.29 \%$ lower than the simulation. Similarly, the measured maximum pressure was $295 \mathrm{MPa}$ which was $4.77 \%$ lower than that of simulation. 
Table 8 The maximum velocity and pressure using steel jacket projectile

\begin{tabular}{cccc}
\hline & Simulation & Experiment & Error \\
\hline Velocity/m/s & 926.55 & 897 & $3.29 \%$ \\
Pressure/MPa & 309.08 & 295 & $4.77 \%$ \\
\hline
\end{tabular}

The difference between simulation result and experiment was within 5\% from Table 7 and Table 8 which showed that the FEM was accurate and available. Besides, the velocity of projectile and average pressure in bore in each situation were shown in Figure 7 and Figure 8. The velocity of copper jacket projectile was higher than the steel jacket projectile. Because steel projectile was heavier than the copper projectile.

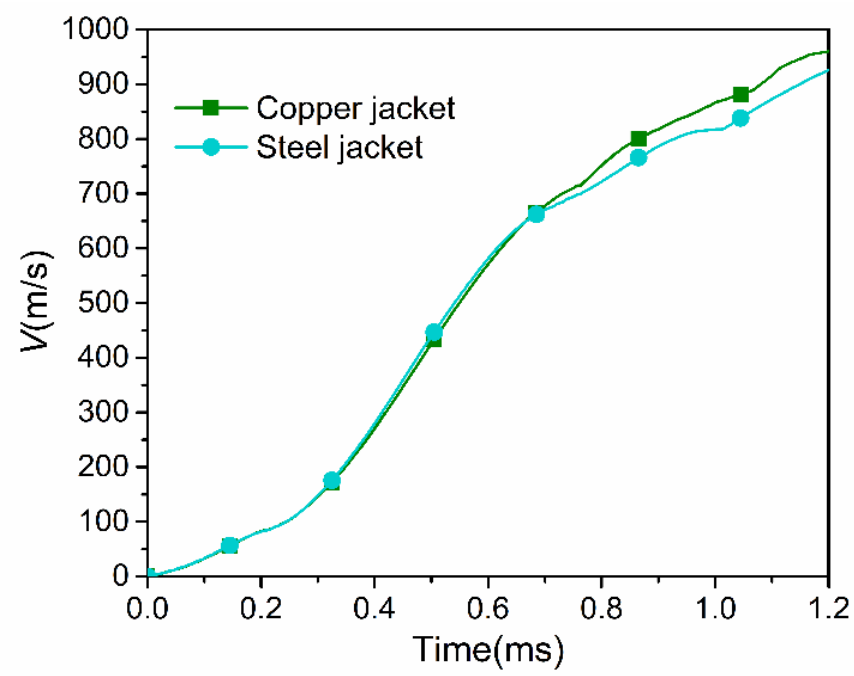

Figure 7. The simulated velocity of the projectile

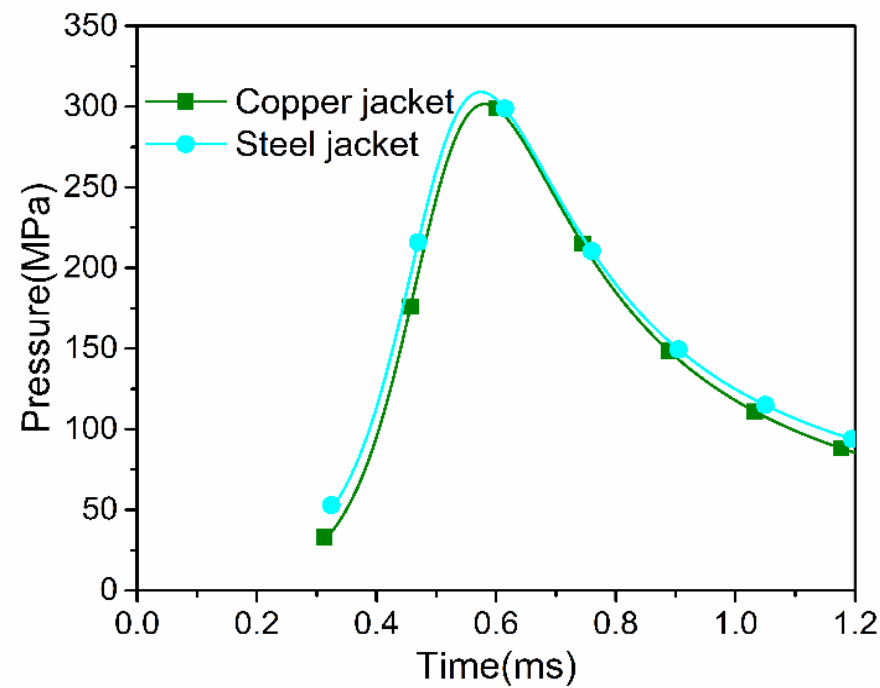

Figure 8. The simulated average pressure in bore

\section{RESULTS}

The endoscope was employed to check the inner bore surface after firing. It was found that where the wear was most serious were the chamber throat and muzzle, as shown within the red circle of Figure 9. Therefore, the analysis would be focused on the chamber throat and muzzle. There are two kinds of regions on the inner wall of barrel, rifling and non-rifling, as shown in Figure 9(a). The stress states of these two regions would be analyzed in the following. 


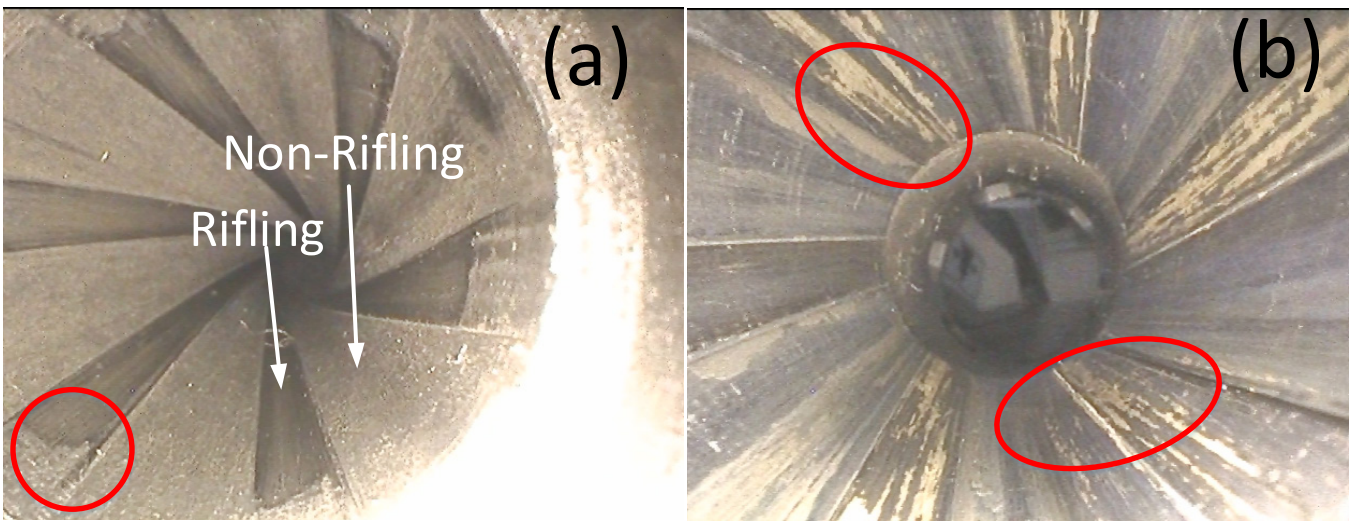

Figure 9. Inner bore surface: (a) Chamber throat (b) Muzzle

\subsection{Copper jacket}

\subsubsection{Chamber throat}

At the end of the coupling process, the maximum temperature and Mises stress of chamber throat were observed at rifling which were $468^{\circ} \mathrm{C}$ and $775 \mathrm{MPa}$, respectively, as shown in Figure 10.

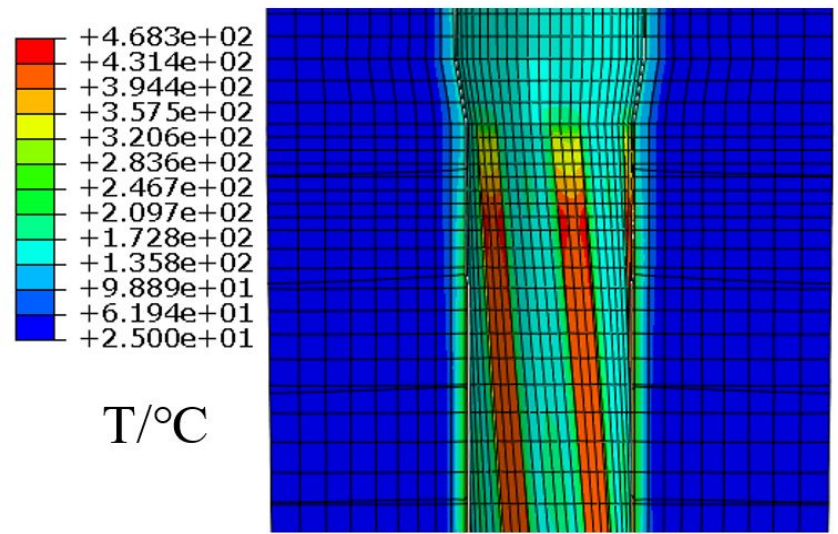

(a)

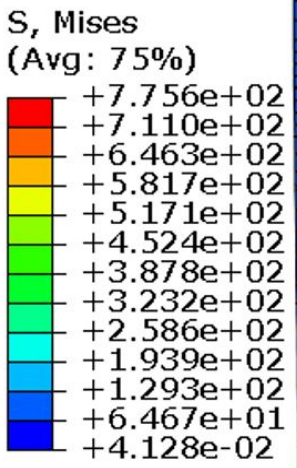

$+4.128 \mathrm{e}-02$

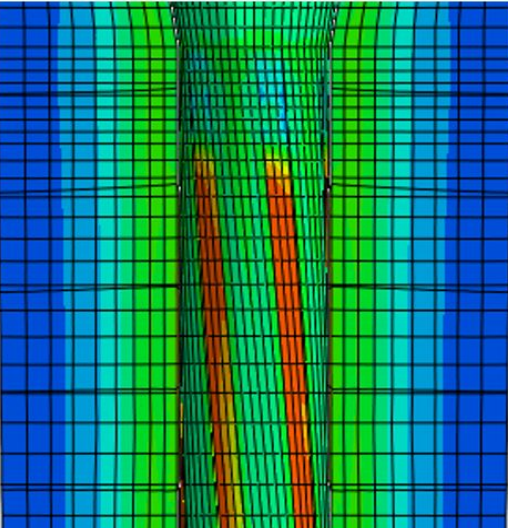

(b)

Figure 10. The chamber throat using copper jacket at the end of coupling process: (a) Temperature (b) Mises stress.

The elements of rifling and non-rifling at the chamber throat were selected to extract the stress state during the whole process. The results were shown in Figure 11. The starting time of was $0.0012 \mathrm{~s}$ which was the end time of the interaction FEM of projectile and barrel. S11 was the radial stress, S22 for circumferential stress and S33 for axial stress. Negative values denoted compressive stress, on the contrast, tensile stress. (the same below).

From the Figure 11(a), the Mises stress of rifling caused by projectile was $860 \mathrm{MPa}$. With the effect of thermal load and pressure load, the Mises stress decreased to 300MPa and then increased to 600MPa. At the end of the coupling process, the value stopped at 500MPa. Radial stress was steadied at 200MPa compressive stress. The circumferential stress and axial stress sharply decreased, changing from tensile stress to compressive stress and then reached the peak of $650 \mathrm{MPa}$ and $820 \mathrm{MPa}$, respectively. The circumferential stress was the largest, 950MPa which had exceeded circumferential yield strength value, 900MPa. Nevertheless, the mechanical properties of 30SiMn2MoVA steel barrel was anisotropy, the circumferential properties were inferior to axial as mentioned in the previous section. Hence, the anisotropy of steel barrel should be considered in the relevant design, especially circumferential properties of gun barrel.

From the Figure 11(b), the Mises stress of non-rifling was smaller than that of rifling. It had a peak value of $445 \mathrm{MPa}$ tensile stress and then gradually stabilized at 350MPa under the coupled loads. The circumferential stress changed from tensile stress $(200 \mathrm{MPa})$ to compressive stress (-100MPa). The axial stress continued to increase and stopped at $-550 \mathrm{MPa}$. 


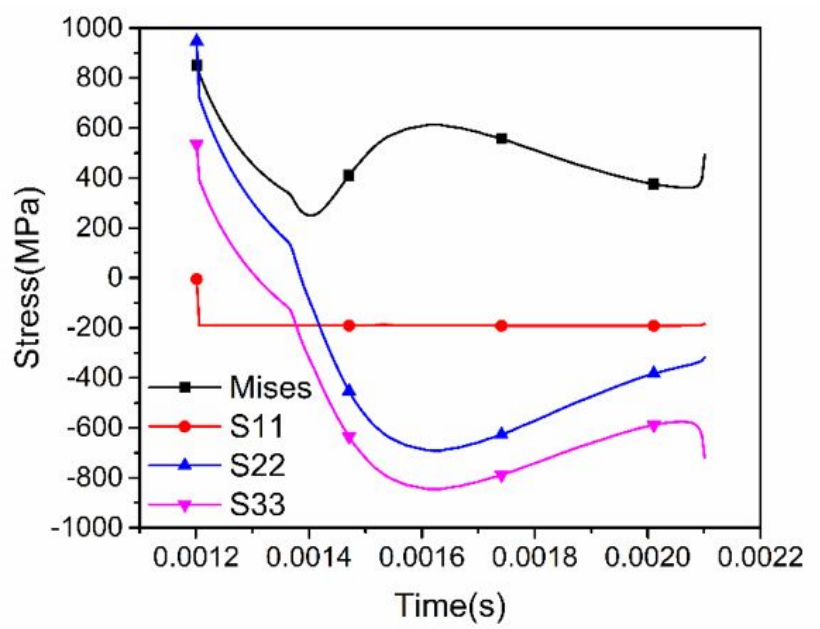

(a)

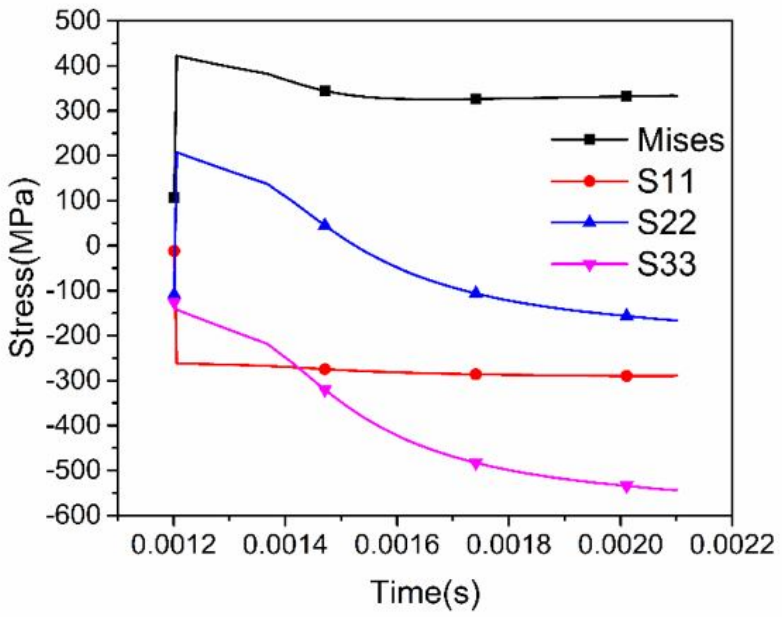

(b)

Figure 11. The stress state of chamber throat using copper jacket during the coupling process: (a) Rifling (b) Non-rifling.

\subsubsection{Muzzle}

At the end of the coupling process, the maximum temperature and Mises stress of muzzle were $399^{\circ} \mathrm{C}$ and $722 \mathrm{MPa}$, respectively, as shown in Figure 12, which was a little smaller than the chamber throat.

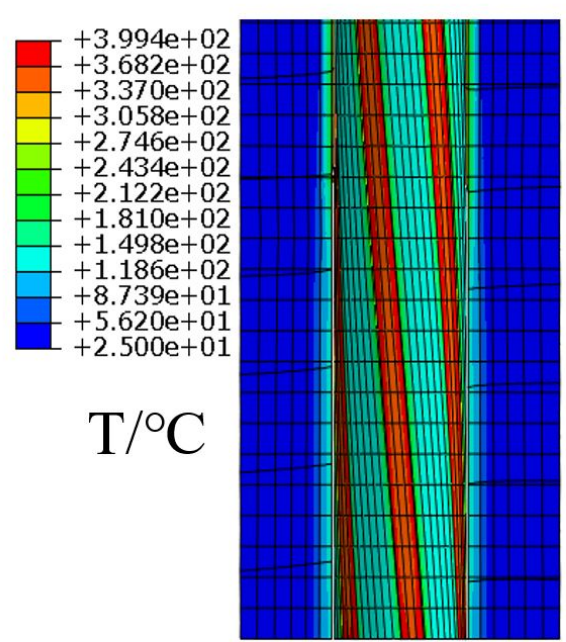

(a)

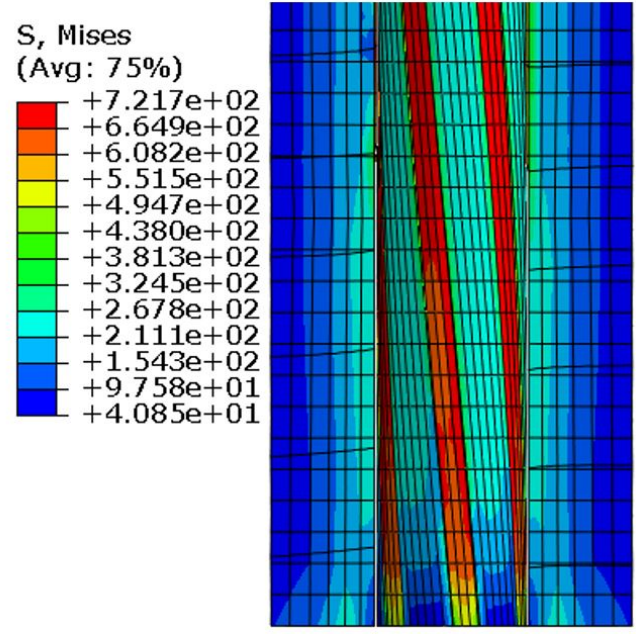

(b)

Figure 12. The muzzle using copper jacket at the end of coupling process. (a) Temperature (b) Mises stress 
From the Figure 13(a), the Mises stress of rifling at muzzle reached the peak value of $800 \mathrm{MPa}$. The radial stress was steady at $100 \mathrm{MPa}$. The axial stress and circumferential stress had the same trend during the process. The circumferential stress increased to $900 \mathrm{MPa}$. The axial stress had a peak value of $870 \mathrm{MPa}$.

From the Figure 13(b), the Mises stress of non-rifling increased under the thermal and pressure load and stopped at $250 \mathrm{MPa}$. The stress in the three direction was mainly compressive stress. The axial stress was the largest, $390 \mathrm{MPa}$. The radial stress was about $80 \mathrm{MPa}$. The circumferential stress gradually changed from tensile stress(100MPa) to compressive stress(-250MPa). At first, the circumferential stress of non-rifling area was tensile stress due to the gas pressure. With the decreasing of the gas pressure and the increasing of temperature of the inner wall, there was temperature difference between the rifling and non-rifling. The temperature of rifling was about $400^{\circ} \mathrm{C}$ from Figure $12(\mathrm{a})$, while the non-rifling was about $100^{\circ} \mathrm{C}$. The rifling expanded and pressed the non-rifling area. So, the circumferential stress of non-rifling area gradually changed to compressive stress.

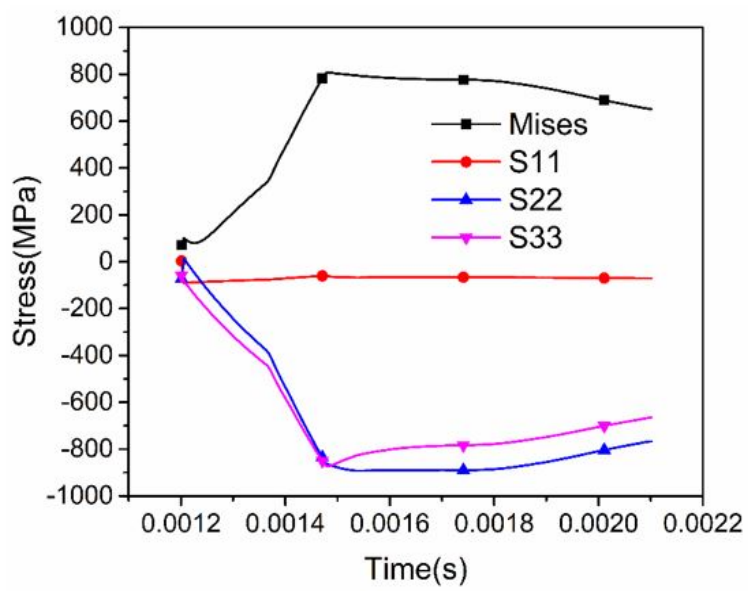

(a)

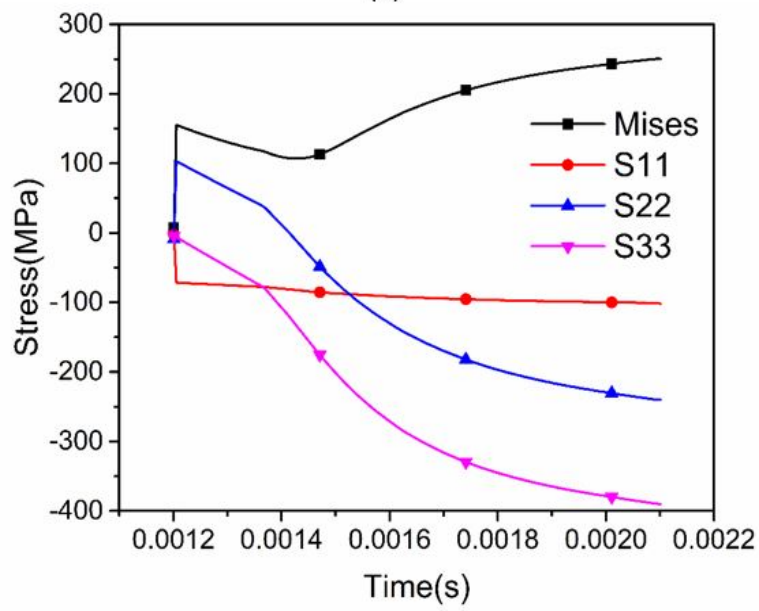

(b)

Figure 13. The stress state of muzzle using copper jacket during the coupling process: (a) Rifling (b) Non-rifling

\subsection{Steel jacket}

\subsubsection{Chamber throat}

At the end of the coupling process, the maximum temperature and Mises stress of chamber throat were $463^{\circ} \mathrm{C}$ and $749 \mathrm{MPa}$, respectively, as shown in Figure 14, which was almost the same as that of copper jacket. 


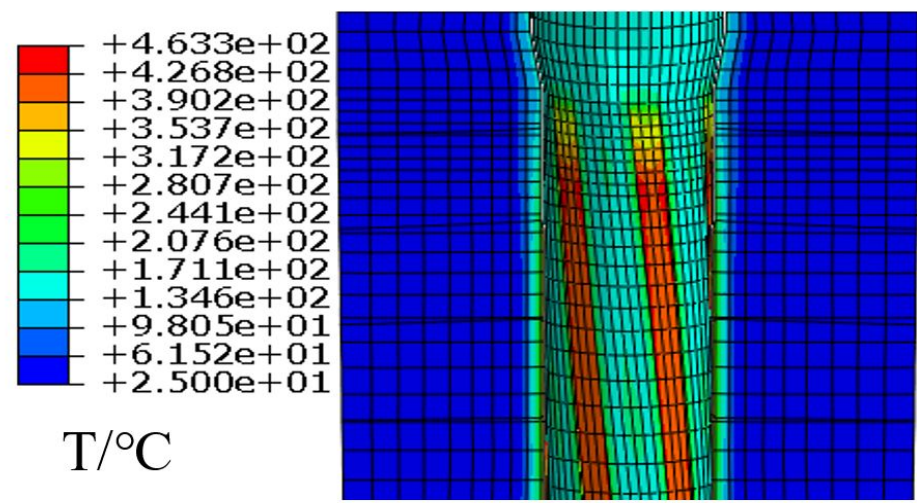

(a)
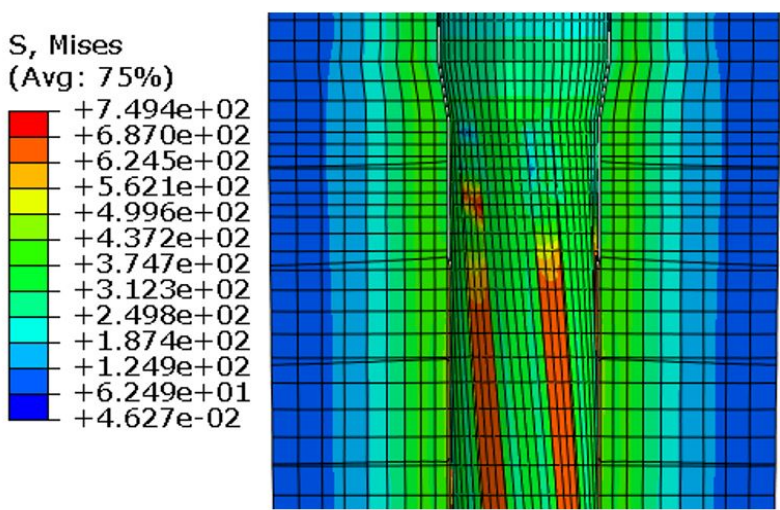

(b)

Figure 14. The chamber throat using steel jacket at the end of coupling process. (a) Temperature (b) Mises stress

From the Figure 15(a), the maximum Mises stress of rifling at chamber throat was 850MPa. After applying with thermal and pressure load, the Mises stress decreased to 500MPa.The circumferential stress was about 1050MPa tensile stress, larger $150 \mathrm{MPa}$ than the circumferential yield strength value stress. Then it converted to compressive stress and reached the peak value of $-700 \mathrm{MPa}$. The radial stress was still stopped at -200MPa. The axial stress changed from 600MPa tensile stress to $1100 \mathrm{MPa}$ compressive stress. The peak value had exceeded the axial yield strength value.

The results of non-rifling were shown in Figure 15(b). The maximum Mises stress was $450 \mathrm{MPa}$. The radial stress was steady at $270 \mathrm{MPa}$ compressive stress. The circumferential stress had a maximum of $200 \mathrm{MPa}$ and then changed to $100 \mathrm{MPa}$. The axial stress was the largest, about -550MPa.

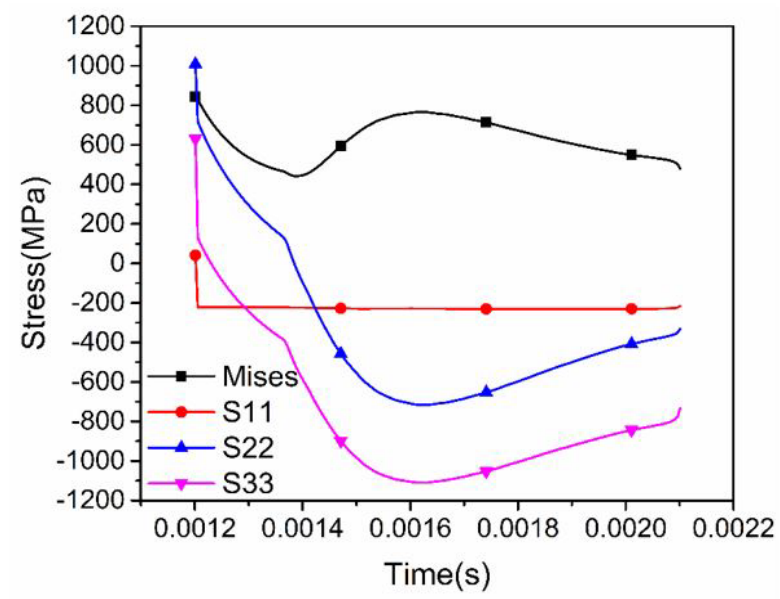

(a)

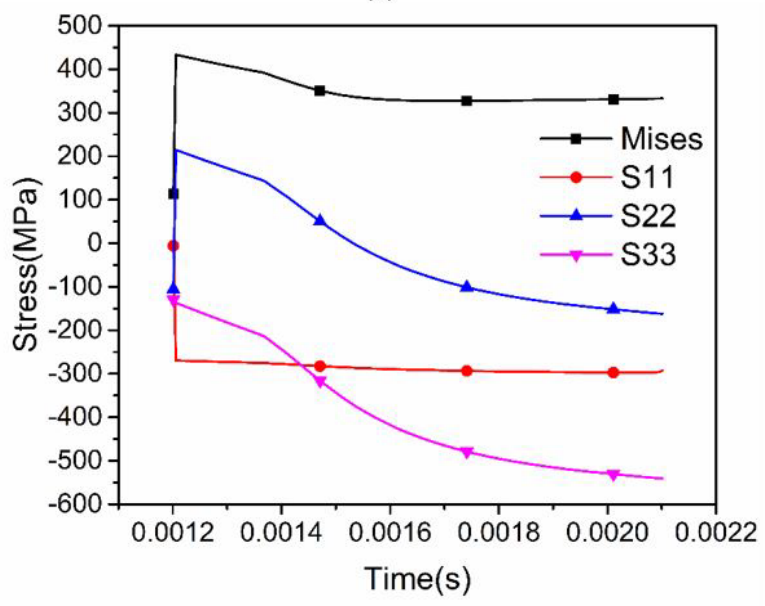

(b)

Figure 15. The stress state of chamber throat using steel jacket during the coupling process: (a) Rifling (b) Non-rifling 


\subsubsection{Muzzle}

The largest temperature and Mises stress of muzzle were $436^{\circ} \mathrm{C}$ and $694 \mathrm{MPa}$, respectively, as shown in Figure 16. That of rifling was still higher than non-rifling.

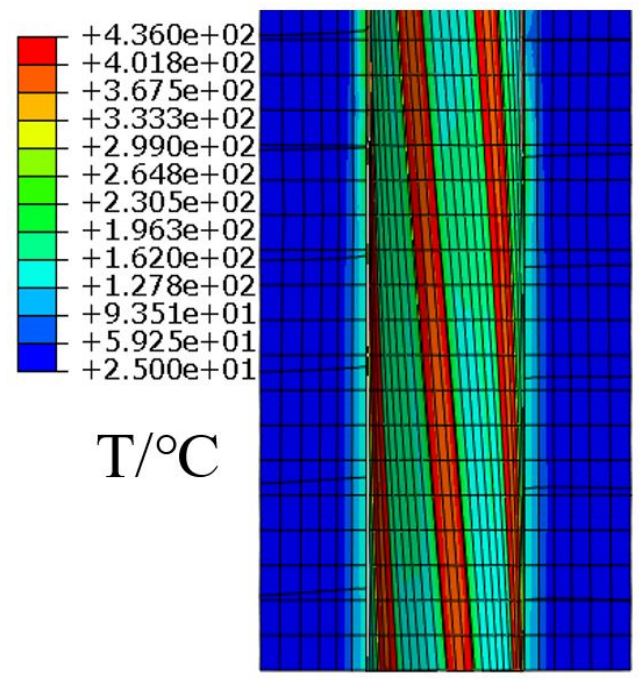

(a)

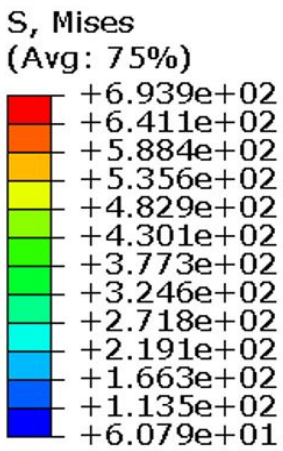

(b)

Figure 16. The muzzle using steel jacket at the end of coupling process. (a) Temperature (b) Mises stress

The largest Mises stress of rifling at muzzle was $800 \mathrm{MPa}$ from the Figure $17(\mathrm{a})$. The radial stress was about $-100 \mathrm{MPa}$. The circumferential stress and axial stress had the same trend. The largest circumferential stress was $-800 \mathrm{MPa}$. The peak value of axial stress was -900MPa.

At the end of coupling process, the stress of non-rifling achieved the maximum, 290MPa, as shown in Figure.17(b). The trend in the three direction was the same as that at chamber throat. 


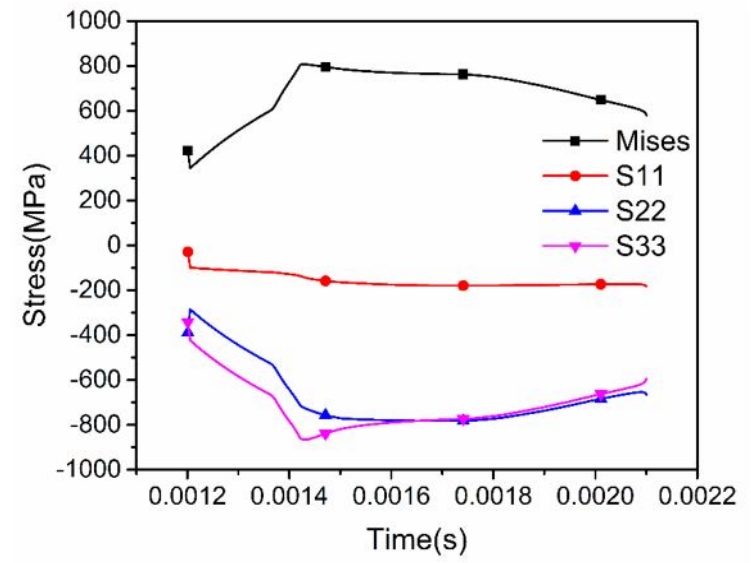

(a)

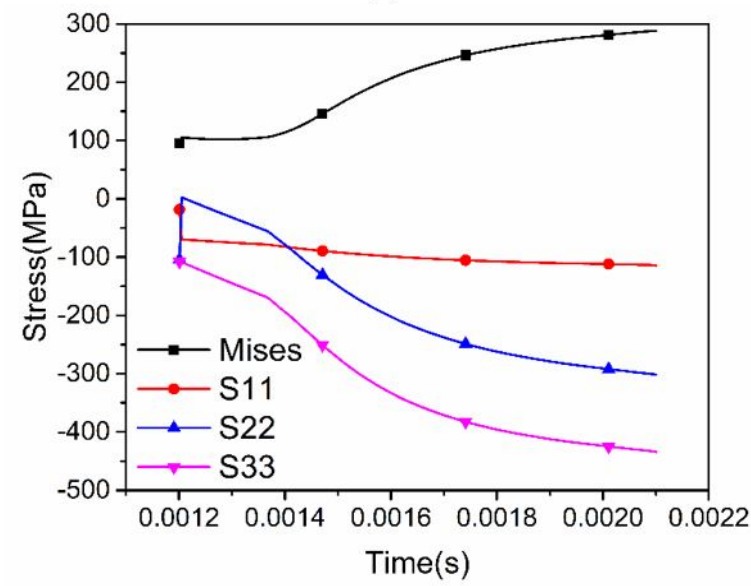

(b)

Figure 17. The stress state of muzzle using copper jacket during the coupling process: (a) Rifling (b) Non-rifling

\subsection{Discussion}

Based on the above, the maximum stress during the whole coupling process of each region was shown in Table 9. The stress of rifling was larger than that of non-rifling. The stress of chamber throat was larger than Muzzle. The stress of firing steel jacket projectile was larger than firing copper jacket projectile. The maximum Mises stress was at chamber throat, which was about $850 \mathrm{MPa}$ (Copper jacket) and 860MPa (Steel jacket). The maximum Mises stresses of Muzzle were about 250MPa (Copper jacket) and 290MPa (Steel jacket). Degirmenci et al. (2016) investigated the stress distribution in bore of a NATO standard small caliber barrel of $7.62 \mathrm{~mm}$ in diameter under propellant gas pressure and thermal load. The maximum Mises stress of chamber throat was about 700MPa and the maximum Mises stress of muzzle was about $250 \mathrm{MPa}$. Their results were a little lower than that in this work due to ignoring the effect of the projectile.

Table 9 The maximum stress in bore

\begin{tabular}{|c|c|c|c|c|}
\hline & \multicolumn{2}{|c|}{ Chamber throat } & \multicolumn{2}{|c|}{ Muzzle } \\
\hline & Rifling & Non-rifling & Rifling & Non-rifling \\
\hline Copper jacket & $\begin{array}{c}\text { 850MPa(Mises) } \\
950 \mathrm{MPa}(\mathrm{S} 22) \\
-820 \mathrm{MPa}(\mathrm{S} 33)\end{array}$ & $\begin{array}{l}\text { 440MPa(Mises) } \\
-550 \mathrm{MPa}(\mathrm{S} 33)\end{array}$ & $\begin{array}{c}\text { 800MPa(Mises) } \\
-900 \mathrm{MPa}(\mathrm{S} 22)\end{array}$ & $\begin{array}{c}\text { 250MPa(Mises) } \\
-400 \mathrm{MPa}(\mathrm{S} 33)\end{array}$ \\
\hline Steel jacket & $\begin{array}{c}\text { 860MPa(Mises) } \\
\text { 1050MPa(S22) } \\
\text {-1100MPa(S33) }\end{array}$ & $\begin{array}{l}\text { 440MPa(Mises) } \\
\text {-550MPa(S33) }\end{array}$ & $\begin{array}{l}\text { 810MPa(Mises) } \\
\text {-900MPa(S33) }\end{array}$ & $\begin{array}{c}\text { 290MPa(Mises) } \\
-450 \mathrm{MPa}(\mathrm{S} 33)\end{array}$ \\
\hline
\end{tabular}

At chamber throat, the stress of rifling was observed that it had exceeded the yield strength. When firing the copper jacket projectile, the gun barrel yielded circumferentially. When firing the steel jacket projectile, the gun barrel yielded circumferentially and axially. And there was plastic deformation at the rifling of chamber throat. The points at chamber 
throat were selected to analyze the results. The distribution and numbering of these points along the inner wall were shown in the Figure 18. The point 1 was on the inner wall. The others were on the rifling.

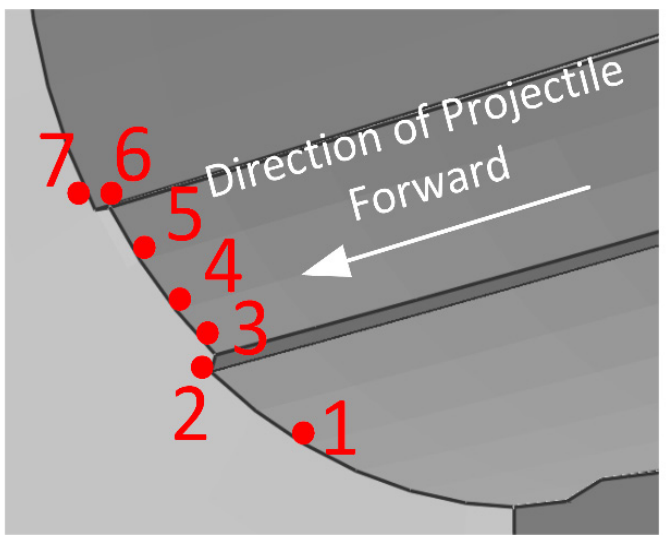

Figure 18. The distribution of selected point.

The results of strain in the bore was shown in the Figure 19. The plastic deformation using steel jacket was higher than that using copper jacket. For steel jacket, the plastic strain was 0.042 . For copper jacket, it was 0.005 . It confirmed that the service life of 30SiMn2MoVA gun barrel firing steel jacket was lower than using copper jacket.

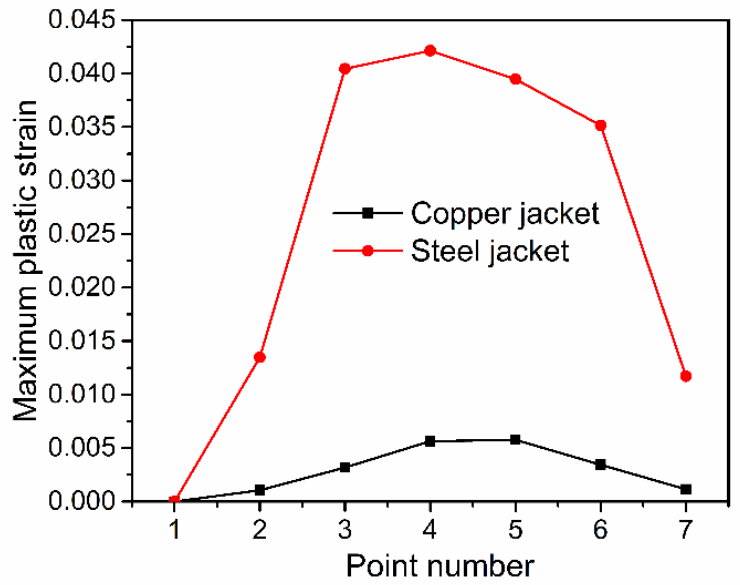

Figure 19. Maximum plastic strain of chamber throat under each condition

In engineering applications, 30SiMn2MoVA steel gun barrel is usually considered as isotropy and only axial mechanical properties are considered for strength checking. From the results in this work, it is inadequate obviously. The 30SiMn2MoVA steel gun barrel has a very low service life in practice. Through the analysis of the inner bore of the end-of-life gun barrel, the main reason for the failure of gun barrel was the shedding of chromium layer. Further observation under electron microscope, the shedding of chromium layer was due to plastic deformation of 30SiMn2MoVA steel substrate at inner bore. The yielding phenomenon of steel substrate was in good agreement with the results obtained in this work although the chromium layer of inner bore was ignored in the FEM model. Therefore, in the strength design of 30SiMn2MoVA steel gun barrel, the anisotropy and coupling thermo-mechanical loads must be considered. Besides, changing the material design, processing parameters and heat treatment process etc. to improve the mechanical properties of 30SiMn2MoVA steel is needed.

\section{CONCLUSIONS}

This work provided a method to calculate the stress response of gun barrel under the coupled thermo-mechanical loads, namely, contact pressure and friction of projectile and thermal and pressure of propellant gas. The anisotropy of 30SiMn2MoVA steel gun barrel and the effect of high temperature on mechanical properties were considered. Based on the above analysis, the conclusions are as follows. 
1) The rifling at the chamber throat had the largest stress under the coupled loads. When firing the copper jacket projectile, the largest stress was the circumferential stress, 950MPa. When firing the steel jacket projectile, it was the axial stress, $1100 \mathrm{MPa}$. The stress of rifling was observed that it had exceeded the yield strength. When firing the copper jacket projectile, the gun barrel yielded circumferentially. When firing the steel jacket projectile, the gun barrel yielded circumferentially and axially.

2) There was plastic deformation at the rifling of chamber throat. The peak values of plastic strain were 0.042 using steel jacket projectile and 0.005 for using copper jacket projectile.

3) In the strength design of 30SiMn2MoVA steel gun barrel, the anisotropy and coupled thermo-mechanical loads should be considered. And the mechanical properties of 30SiMn2MoVA steel, especially, the circumferential yield strength should be improved.

\section{Acknowledgements}

This work was supported by the National Defense Basic Scientific Research Program of China (JCKY2016209A002).

Author's Contributions: Conceptualization, $Y$ Yang; Methodology, $Y$ Yang; Investigation, $Y$ Yang and $X$ Zhang; Writing original draft, Y Yang; Writing - review \& editing, Y Yang and X Zhang; Funding acquisition, L Fan and C Xu; Resources, L Fan and CXu; Supervision, L Fan.

Editor: Marcílio Alves.

\section{References}

Cao S., Xu C., (2017) Experimental on influence of temperature on mechanical properties of barrel in material 30SiMn2MoVA.Journal of Ordnance Equipment Engineering 2: 159-162.

Chen J., Young B., Uy B., (2006) Behavior of high strength structural steel at elevated temperatures. Journal of Structural Engineering 132(12):1948-1954.

Ding C., Zhang X., Liu N., (2016) A parametric modeling method for gun barrel and a meshing generation strategy for worn barrel. Acta Armamentarii 37(12):2212-2219.

Ding C., Zhang X., (2015) Simulation study of bearing band engraving process and interior ballistic process based on thermomechanical coupling FEA model. Acta Armamentarii 36(12): 2254-2261.

Dassault Systemes., (2014) ABAQUS 6.14 Analysis User’s Manual. Waltham, USA: Dassault Systems Inc.

Degirmenci E., (2015) Semi-empirical prediction of internal pressure distribution and muzzle velocity in the rifled barrel of a light weapon. Measurement 70: 123-128.

Degirmenci E., Dirikolu M. H., (2012) A thermochemical approach for the determination of convection heat transfer coefficients in a gun barrel. Applied Thermal Engineering 37:275-279.

Degirmenci E., Evci C., Isık H., (2016) Thermo-mechanical analysis of double base propellant combustion in a barrel. Applied Thermal Engineering 102:1287-1299.

Evci C., Gülgeçb M., (2018) Functionally graded hollow cylinder under pressure and thermal loading: Effect of material parameters on stress and temperature distributions. International Journal of Engineering Science 123:92-108.

Fan L., Hu Z., Zhao J., (2006) Thermo-mechanical analysis of water-cooled gun barrel during burst firing. Journal of China Ordnance 2(1):1-6.

Gu Z., Xu C., Cao S., (2018) Three-dimension finite element analysis on state difference between hot gun and cold gun in typical small caliber rifle barrel system. Journal of Ballistics 30(2):47-53.

Güngor O., Çelik V., (2018) Numerical evaluation of an autofrettaged thick-walled cylinder under dynamically applied axially non-uniform internal service pressure distribution. Defence Technology 14(05):62-66.

Hill R., (1950) The Mathematical Theory of Plasticity, Oxford University Press: Oxford, United Kingdom. 
Jiang X., Chen Z., Fan B., (2008) Numerical simulation of blast flow fields induced by a high-speed projectile. Shock Waves $18(3): 205-212$

Johnson G. R., Cook W. H., (1985) Fracture characteristics of three metals subjected to various strains, strain rates, temperatures and pressures. Engineering Fractures Mechanics 21(1):31-48.

KEINANEN H., MOILANEN S., TERVOKOSKI J., (2012) Influence of rotating band construction on gun tube loading part I: numerical approach. Journal of Pressure Vessel Technology 134: 0410061-0410067.

Liu L., Fan L., Dong X., (2012) Experimental study of the mechanical property of barrel processed by cold radial forging, Journal of Beijing Institute of Technology 2:453-459.

Li M., Qian L., Sun H., (2016) Research on coupled thermo-mechanical model during rotating band engraving process. Acta Armamentarii 37(10):1803-1811.

Liu G., Sun H., Zhou W., (2015) Numerical simulation for gun barrel bore damage during shells with into bore. Journal of Vibration and Shock 34(13):78-82.

Li X., Mu L., Zang Y., Qin Q., (2019) Study on performance degradation and failure analysis of large caliber gun barrel. Defence Technology https://doi.org/10.1016/j.dt.2019.05.008.

Lawton B., (2001) Thermo-chemical erosion in gun barrels. Wear 251(1-12):827-838.

Lan W., Yang Z., (2017) Analysis of the effect of thermal deformation of barrel on rifle firing. Journal of Ordnance Equipment Engineering 38(10): 25-29.

Noh J. H., Kwak D. B., Kim K. B., (2018) Inverse heat conduction modeling to predict heat flux in a hollow cylindrical tube having irregular cross-sections. Applied Thermal Engineering 128: 1310-1321.

Qu P., Li Q., Yang S., (2014) Temperature field and thermal stress analysis of large caliber gun barrel. Applied Mechanics and Materials 518:150-154.

Saux M. L, Besson J., Carassou S., (2008) A model to describe the anisotropic viscoplastic mechanical behavior of fresh and irradiated Zircaloy-4 fuel claddings under RIA loading conditions. Journal of Nuclear Materials 378(1):60-69.

Wu B., Zheng J., Tian Q., (2014) Friction and wear between rotating band and gun barrel during engraving process. Wear 318(1-2):106-113.

Wu B., Xia W., (2005) Heat transfer in gun barrel based on inverse heat conduction problems. Acta Armamentarii, 26(3):299302.

Xu X., Fan L., Wang Y., (2016) Trans-scale polycrystalline finite element simulation of radial forging process for barrel and prediction of texture. Acta Armamentarii 37(7):1180-1186.

Yu Q., Yang G., (2018) Dynamic stress analysis on barrel considering the radial effect of propellant gas flow. Journal of Pressure Vessel Technology http://doi.org/10.1115/1.4041974

Yang Y., Xu C., Fan L., (2018) An analysis of motion of projectile in bore with the change of material properties of copper armor due to high temperature. Acta Armamentarii 39(6):1074-1081.

Yuan Y., He G., Zhang Y., (2012) Analysis of tensile property and microstructure of F18 copper clad steel. Metallic Functional Materials 19(2):47-54.

Zhao S., Guo S., Pan C., (1997) Discussion on strength theoretical problems of barrel. Journal of Technology of Armed Police Force 13(1):52-54.

Zhang Z., Qin T., Fu Q., (2015) Error analysis of theoretical calculation and numerical calculation of the gun barrel strength. Ordnance Industry Automation 1:28-31.

Zhu D., Zhang L., Pei J., (2008) Experiment research on the thermal contact conductance during the solid plastic forming. Journal of Plasticity Engineering 15(1):92-96. 